\title{
Developing a Sustainable Concept for Urban Last-Mile Delivery
}

\author{
Patrick Siegfried', John Jiyuan Zhang² \\ ${ }^{1}$ International Management, Logistics \& Supply Chain Management, International School of Management, Frankfurt, Germany \\ ${ }^{2}$ International Management, International School of Management, Hamburg, Germany \\ Email: patrick.siegfried@ism.de, johnjiyuan.zhang@hotmail.com
}

How to cite this paper: Siegfried, P., \& Zhang, J. J. (2021). Developing a Sustainable Concept for Urban Last-Mile Delivery. Open Journal of Business and Management, 9, 268-287.

https://doi.org/10.4236/ojbm.2021.91015

Received: December 12, 2020

Accepted: January 22, 2021

Published: January 25, 2021

Copyright () 2021 by author(s) and Scientific Research Publishing Inc. This work is licensed under the Creative Commons Attribution International License (CC BY 4.0).

http://creativecommons.org/licenses/by/4.0/

\section{(c) (i) Open Access}

\begin{abstract}
In relation to the fast development of e-commerce and rapid increasing of parcels, urban logistic sector is facing the challenge of sustainability. Especially, last-mile delivery as the last step of goods transport, it connects to customers' satisfaction, cost efficiency of logistic companies, and more and more public expectations to sustainability of urban logistics. To handle with the complexity of urban logistics conditions, governments and logistics companies should develop a co-operating strategy for sustainability of urban last-mile delivery. This paper is based on data collection from the long-term empirical research and a survey to the e-commerce users in Germany and China to develop a sustainable concept for the urban last-mile delivery. The key to the development of concept is to create a balance among the requirements of customers, the competition abilities of logistics companies and the public interest.
\end{abstract}

\section{Keywords}

Last-Mile Delivery, Urban Logistic, Sustainability, Sustainable Delivery,

E-Commerce, Parcel Delivery, Logistic Solution

\section{Introduction}

Since 21st century, the consumer behavior has been deeply changed by E-commerce. In comparison to traditional real store trade, e-commerce provides customers various advantages, such as low price, wide range of selection, more convenience of shopping, and time saving. E-commerce is open for consumers 24 hours every day. With connection of internet, people can go shopping online anytime and anywhere (Siegfried, 2014b).

At the same time, because of the fast growing of e-commerce, the number of parcels is increasing rapidly every year. Especially in the urban areas, how to de- 
velop a sustainable last-mile delivery strategy has become one of the most difficult challenges of logistic sector. Urban last-mile delivery is facing the challenges of high costs, small-size delivery, "not at home", lack of infrastructure, congestion, and high workloads. Last-mile delivery relates not only to customer's satisfaction, but also cost efficiency for parcel delivery companies, environmental issues, and congestion for urban citizens.

The key to develop an urban sustainable last-mile delivery concept is to create a balance among the requirements of customers, competition abilities of parcel delivery companies and public interest. This research is based on long-term practical experience in a package shop in Hamburg of Germany and the data collection from a survey for e-commerce users in Germany and China. In addition, through interview with package shop customers are many empirical data collected for this paper.

The concept is divided into two parts. The part of government's aspect, which focuses on regulations of urban last-mile delivery, improvement of infrastructures, and global sustainability standards. The second part is based on company's long-term strategies, which consist of usage of environmentally friendly vehicles, advanced personal management, and development of new stational parcel shops.

\section{Background}

Globally online retail business segment has made 2.68 trillion euros in sales in 2017. In 2023, the sales of online retail globally would reach to 5.99 trillion euro. E-commerce penetration has steadily been on the rise with online shopping share of retail spend registering $10.5 \%$ in 2016, rising to $12.3 \%$ in 2017 and closing out 2018 at 14.4\% (Young, 2019). Moreover, according to Statista (2020b), the number of e-commerce users increased from 2.4 billion in 2017 to 3.1 billion in 2019 globally. This number will rise to around 5 billion in 2025 and $63.1 \%$ of world population will become the active e-commerce users as reported by Statista (2020b). In addition, due to the development of communication technology, mobile e-commerce and social media will rapidly gain in importance, the large number of smartphone users contribute to the developing of online shopping (Schöder et al., 2016).

In term of e-commerce, parcel shipping is a booming business. Increasing use of e-commerce is the primary driver generally cited for the growth of the global courier, express and parcel (CEP) market, as e-commerce relies on CEP companies (along with local postal services) to deliver goods to consumers. This is the case across all regions. In total, there were 87 billion parcels shipped worldwide in 2018, which reveals growth of $17 \%$ in 2018. The annual report of Pitney Bowes' Parcel Shipping Index forecasts that by 2025, this figure will more than double to 200 billion parcels. By 2019, according to Statista (2020a) the global courier, express and parcel market is expected to be worth over 330.4 billion euro, it was around double increasing compare to 2009 (157.45 billion euro).

Moreover, "Smart cities" have become the development direction pursued by 
city leaders to address challenges related to rapid growth in urban areas. In most cases, smart cities revolve around initiatives that use digital innovation to make urban service delivery more efficient and thereby increase the overall competitiveness of a community (OECD, 2020). The sustainable development of the logistics sector has important practical significance for the evolution of smart cities (Lan et al., 2020). With continued growth in global trade and e-commerce fueling parcel delivery volumes, there is a growing need for environmentally and neighborhood friendly solutions to last-mile delivery in cities and logistics operations (DHL Group, 2020).

\section{The Current Challenges of Urban Last-Mile Delivery}

\subsection{High Costs of Last-Mile Delivery}

The Capgenini (2019) report shows that the costs of last-mile services account for $41 \%$ of overall supply chain costs. It is more than double any other category of spend, such as parceling or warehousing. In e-commerce sector, last mile delivery could reach around 75\% of the whole freight costs (Wang et al., 2016: pp. 279-293). In term of consumer-driven economy, most e-commerce platforms are trying to provide fast delivery for customers to satisfy the consumers' requirements. Many people have a belief that online products must be shipped as soon as possible after the order is made. This is usually perceived as important by electronic retailers to match the service levels offered by their competitors.

If customers could have a sustainable considering, they will realize that free shipping is not suitable for a particular from the environmental and social perspectives. According to Capgenini (2019), younger consumers (30-year-old or younger) are willing to pay the highest across all age groups for faster deliveries.

\subsection{Small-Size and Increasing Demand of Faster Delivery}

E-commerce customers are increasingly demanding faster transportation and with increased service quality (Siegfried, 2014a). These changes driven by e-commerce bring business opportunities to the logistics service providers, particularly couriers handling parcel delivery, delivering goods to each customer's home quickly and reliably in small batches. The most significant impact of e-commerce on urban logistic is the increase in direct home delivery of smaller shipments (Siegfried, 2013).

Responding to the increased demand of small-sized frequent shipments incurred by e-commerce has become one of the biggest challenges for logistics express delivery companies. A successful delivery of shipments to consumers distributed across large geographical areas will require re-designing of the existing distribution network including terminals, hubs, and the network paths that connect them (Aranko, 2013).

\section{3. "Not-at-Home" Problems}

Because of long working hours in the cities, many home deliveries could fail be- 
cause people not at home. If that, the parcels will be left at parcel shops or depots. It leads to longer delivery path and more environmental issues. A major factor for the success of home delivery operations is whether there is someone at the customer's home to receive the delivery. Several social and economic factors are leading to homes being empty for longer periods in a day than they used to be. Some of these are inflexible working patterns, long commutes, increases in working women, and the growth in single-person households. This results in a relatively high proportion of first-time delivery failure, causing higher operating costs for carriers and lower customer satisfaction (Park \& Regan, 2004).

With a growing number of houses empty during the daytime and the standard delivery times between 8 am and $5 \mathrm{pm}$, the difficulties are obvious. There is clearly a need to better understand when customers want to receive deliveries, and then meet these needs.

\subsection{Lack of Urban Logistic Infrastructure}

In many cities, the urban infrastructures are having existed for a long time and some facilities have become old. Especially, numerus apartments of high building have no lifts for goods transportation, that leads to a lowly effectivity of parcel delivery. Meet to this situation, urban last mile delivery should not only be considered horizontally (point to point), but also be considered as an integrational process with horizontal and vertical delivery (three dimensions).

The map in Figure 1 shows some examples of the critical points of urban last mile delivery. If all buildings in the map do not have lift for transportation, to

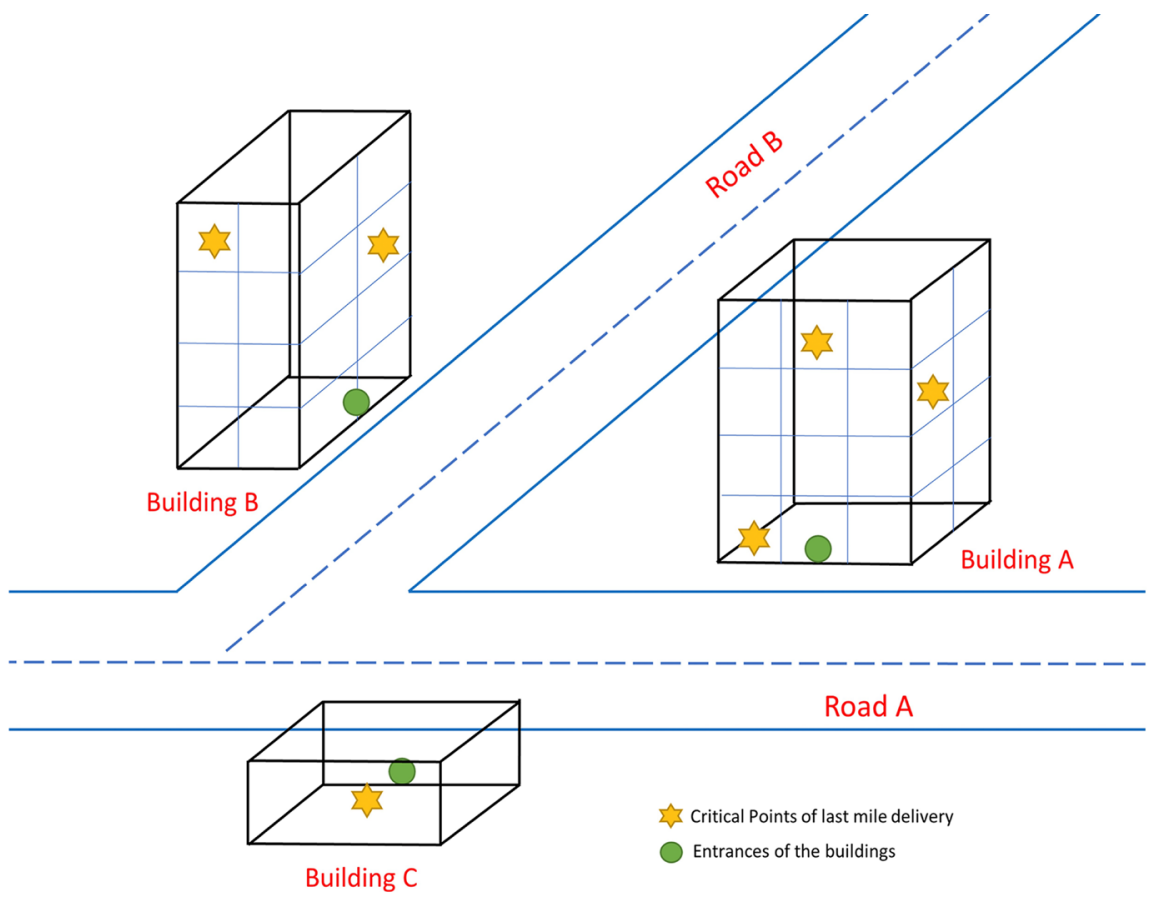

Figure 1. Critical points of the current last mile delivery in urban areas; Source: author's own creation. 
deliver parcels into building B would be more difficult than to deliver into build $\mathrm{C}$ or into the first floor of building A. To transport oversize or overweight goods, such as furniture or lager home appliances, the problem might be more strenuous for parcel drivers. Because they usually do not have any special equipment to transport lager and heavy parcels for high floor buildings and parcels must be carried by themselves. Besides that, many stairwells of old buildings in urban areas are exceedingly narrow. Therefore, the transportation process in inside of those buildings might be extremely exhausting. Obviously, if goods lifts could be built in the old buildings, home delivery would be more effective. While lots of transport time could be saved through use of goods lifts, workloads of parcel drivers could be reduced significantly as well.

In addition, in most urban resident areas the parking spaces are extremely limited. Parcel drivers must spend lots of time to find a park place. Usually, they would not park at a legitimate place due to a faster delivery. Therefore, if some fixed delivery park places could be set up in the near of resident areas, the transport could be more flexible, and many unnecessary congestions would be avoided.

\subsection{Workloads of Parcel Drivers}

Workloads for parcel deliverers have risen substantially in recent years. Nowadays, parcel couriers would deliver much more parcels than a decade ago. But while the number of packages has risen steadily, the cost of sending them has not. Giant retailers like Amazon put pressure on delivery companies and the price per package delivered keeps falling (Schaer, 2018).

Time pressure and pressure to perform have risen accordingly. Parcel deliverers across the board are complaining about growing physical and mental stress. Price wars are primarily fought on the backs of couriers. Parcel service providers want to cut their costs to keep prices down from their competitors (FORBA, 2018). Some parcel deliverers must curry oversize or very heavy parcels to customers like washing machines or furniture many times in every single day. Moreover, employees and self-employed parcel deliverers in many cases do not receive a fixed income but instead are paid per delivery. Thus, they are forced to work extremely long hours to cover their costs. Couriers are contracted by subcontractors and sometimes even by sub-subcontractors (FORBA, 2018).

\subsection{Congestion}

A high proportion of freight and service transport in cities takes place during peak hours on the road network. At the same time, trends in supply chains and logistics management together with changes in the behavior by business and private consumers are leading to increased fragmentation of last mile deliveries. The combined result of this is that more vehicles are trying to make more deliveries at the same time and the infrastructure available (road space and curbside space) cannot cope (Browne et al., 2017). Demand for urban last mile delivery is 
expected to grow by four-fifths (78\%) by 2030 , leading to $36 \%$ more delivery vehicles in inner cities. In turn, traffic congestion is forecast to rise by over $21 \%$, the equivalent of adding 11 minutes to each passenger's daily commute, according to The Future of the Last-mile Ecosystem analysis (Weekes, 2020).

In major cities, commonplace obstacles like road closures, construction, heavy traffic, and even parking restrictions make the last mile remarkably time- and energy-consuming. Transport processes are the origin of air pollution and waste such as tires, oil, and other materials. Air pollution is an especially burdensome factor because it means harm to people's health as well as deterioration of living conditions (Mesjasz-Lech, 2016). Last-mile Logistics is considered as the most expensive and polluting segment in the entire supply chain network. With increasing concerns over the impact of this segment on environment, necessary steps were taken to reduce the Greenhouse Gas (GHG) emissions (Awwad et al., 2018). A recent study of EU countries shows that in $60 \%$ of cities, there are significant difficulties in terms of urban logistics management; $55 \%$ of vehicle emissions are caused by goods distribution (Faccio \& Gamberi, 2015).

\section{Concept for a Sustainable Urban Last-Mile Delivery}

A cocktail of solutions can be applied to improve last mile delivery of goods in cities. Each of these solutions has already demonstrated benefits in selected cities. Several of these solutions have existed for many years, but the complexity lies in selecting the right combination of solutions, taking into account the local context and the solution's contribution to the defined objectives at local level (Van Audenhove et al., 2015).

\subsection{Regulations for Urban Last-Mile Delivery}

Accroding to Van Audenhove et al. (2015), regulatory and land planning measures allow authorities to impose certain rules and restrictions on the use of urban transportation and land planning for logistics within the city.

Restricted access to certain areas: based on a set of criteria for vehicles (e.g. emissions, weight, size) (Van Audenhove et al., 2015). The European Union (EU) has committed to a long-term goal of limiting the rise of 20 Celsius in global average temperature. The United States has agreed to collaborate with over 180 nations under the United Nation (UN) Framework convention on climate change to bring about the "stabilization of greenhouse gas concentration in the atmosphere to a level that would prevent dangerous anthropogenic interference with the climate system". It has been found that for more than 20 Celsius rises in global temperature, there are severe risks to natural systems and human health. Continued rise of this level could even lead to extinction of many species and rise in the global sea level between 12 and 40 feet. These numbers are high and alarming and with increasing concerns on global warming, the government across globe has decided to work towards reducing the $\mathrm{CO}_{2}$ emissions. It has been studied that to avoid temperatures rising above 20 Celsius, countries must 
stabilize concentration of heat trapping gases in the atmosphere at or below 450 parts per million $\mathrm{CO}_{2}$. For this target to be achieved, the U.S. must reduce its emissions by a minimum of 80 percent below the 2000 levels by the end of 2050 . With the forecasted rise in sales in e-commerce industry being so high and with such far-fetched targets for emissions reductions, the companies are forced to develop initiatives to control their $\mathrm{CO}_{2}$ emissions. Various initiatives have been taken by companies across globe to reduce $\mathrm{CO}_{2}$ emissions (Awwad et al., 2018: pp. 584-591).

Time slots for when certain vehicles can enter certain streets, such as off peak hours delivery (OHD) (Van Audenhove et al., 2015). For example, the creation of peak-hour freight-free zones in central Melbourne and activity centres would alleviate road congestion and provide for more efficient freight delivery.

In Mexico City, city officials created "Hoy No Circula" (no drive days) to combat congestion and pollution. Under this scheme, the last digit of a license plate determines which day a vehicle cannot be operated. While well intended, citizens as well as logistics operators began incorporating additional vehicles to increase their transportation options. Vehicles were purchased or leased based on availability and affordability, rather than environmental soundness. According to a Cal State University Los Angeles study, this scheme over time has resulted in a 13 percent rise in carbon monoxide levels and has had little impact on alleviating congestion. In European cities where access restrictions are based on maximum vehicle size, they may be solving for one problem while creating others. To meet demand, carriers must deploy a greater number of smaller vehicles, and that can also increase congestion as well as GHG emissions, and deteriorate air quality, depending on the vehicles used (UPS \& GreenBiz, 2017).

In some cities, for example Brussel, the initiative of OHD was satisfactory from an environmental, economic and mobility perspective, however noise regulations within the region made it impossible to adhere to the regulatory standards (Browne et al., 2017).

Exclusivity zones for urban deliveries (in which only one or a limited number of transporters can perform deliveries) should be established (Van Audenhove et al., 2015). Across many different cities worldwide, first pilots and initiatives are already in place or are soon to be launched. For instance, in Amsterdam, the action plan called Actieplan Schone Lucht has been set up this year and shifts the conversation "from the inside to outside" and "from business to private". Thereby, the ultimate objective is to offer emission-free traffic in the entire city center by 2030, banning diesel and other combustion engines by 2025 for commercial purposes.

All of these measures are usually applied in combination with other last mile delivery levers as they can steer the behavior of transporters towards better last mile delivery solutions. Restrictions and time slots are mature levers, as they have been applied for a number of years in many cities. As these measures imply 
a large capital cost for transporters (e.g. new or retrofitted vehicles), cities need to align in order to make the compliance costs for transporters as low as reasonably possible. Due to the size of these compliance costs, implementation favors large transport operators over smaller ones. Authorities must also ensure that these levers are effective by enforcing them (e.g. by using fines), and prioritize enforcement of existing measures over introduction of new ones.

\subsection{Infrastructure of Distribution Facilities}

To meet customer demands for same-day instant delivery, there is a growing trend for companies to build or take advantage of urban warehouse space. Also, city hubs, micro hubs and shopping areas (within the city) will play an important role in decoupling slow, large scale mobility from personalised, small scale mobility. City hubs will be "white label" and will be developed in public-privatepartnerships (Van Amstel, 2017).

An urban distribution center (UDC) collects shipments in a specialized warehouse at the edge of the city, where they are consolidated before being shipped into the city for last mile delivery (Van Audenhove et al., 2015). The objective is to increase truck usage to optimize the total distance traveled by trucks, which benefits the city's congestion level and air quality. The UDC's impact depends mainly on the extent to which it can increase truck usage, which is influenced by the nature of the goods, the transporters and the local density. Although many are no longer in operation due to lack of financial viability, people expect to see a second wave of UDC implementations, building on the lessons learned from the previous implementations.

The introduction of ultra-low emission zones and clean air zones encourage parcel companies to invest in more zero emission vehicles. Those not meeting emissions standards required by zones will face strict penalties. It is likely that more cities will see similar penalties for non-compliant vehicles, or financial incentives to encourage the take-up of zero emission vehicles for the last mile. Local government will introduce performance-based regulation with digital reinforcement.

Cities can also reserve dedicated parking spaces for (un)loading trucks in the city, or let trucks use bus lanes during certain times of the day (Van Audenhove et al., 2015). While this measure is already widely adopted, recent implementations of this lever use dynamic reservations of parking spots or dynamic access allocation of bus lanes for trucks, depending on the time of day or the current traffic conditions.

E-commerce pick-up points, such as Amazon's Lockers should be established to meet the recent surge in e-commerce that has led to an increase in parcel deliveries. It enables transporters to deliver parcels to single locations without having to go from door to door. They also allow customers to pick up their packages at their own convenience, from locations close to their homes (Van Audenhove et al., 2015). 


\subsection{Financial Incentives}

Public authorities can give financial incentives to urban transportation providers based on a supply-demand mechanism, to steer their transportation decisions and lower the externalities caused by urban freight transport (Van Audenhove et al., 2015).

Urban congestion charges for certain roads or areas in the city can incentivize transporters as well as car users to reduce traffic in those areas, which leads to lower congestion. Secondary benefits include reduced air pollution and greenhouse gas emissions. The charges can be made using toll booths or automated fare collection systems based on license plate recognition, or by installing a signaling device in the vehicle. Implementing this measure requires hefty investments, which are usually made via public-private partnerships and can be politically sensitive.

The United States, with its ingrained love affair with the automobile, has been slower to be as aggressive as Europe has with ditching diesel from downtowns, but some American cities are trying out initial programs. New York will be the first U.S. city to adopt congestion pricing at the end of 2020; it will charge car and truck drivers to enter Manhattan's city center. Car drivers could be charged between $\$ 12$ and $\$ 14$ to enter the restricted zone. Truck drivers could be charged about $\$ 25$ per entry (Fehrenbacher, 2020).

Congestion pricing was introduced in Stockholm as a 6-month trial in 2006, and then reintroduced in August 2007. Prior to the congestion charge, the average number of vehicles traversing the cordon per day ranged between 380 480,000 , with $18 \%$ estimated to be freight traffic. The short-term effect of the congestion pricing trial was a reduction by $20 \%-22 \%$ in traffic crossing the cordon; a 20\% reduction was sustained over the long term (Browne et al., 2017).

A variable smart fare depending on a set of variables, such as distance traveled, volume shipped, or the time of the day can optimize a tolling system. Pricing schemes based on global satellite navigation systems can allow for accurate, usage-based pricing instead of plain "access fees", charging only those vehicles that contribute the most to congestion. Subsidies, tax deductions and other incentives to foster the implementation of infrastructure, equipment, or technology levers (Van Audenhove et al., 2015).

\subsection{International Sustainability Standards}

\subsubsection{United Nations Environmental Programmer's (UNEP)}

UN Environment promotes sound environmental governance-the rules, policies and institutions that shape how humans interact with the environment. By building robust governance systems, the environment and human rights and work can be safeguarded toward all 17 UN Sustainable Development Goals.

United Nations Environment Program helps governments lay the foundations for smart environmental laws and policies that help protect the environment from degradation and fulfil environmental and human rights obligations. The 
partnerships-with national governments, judges, parliamentarians, enforcement officers and other policymakers - are one of the greatest assets. Through these partnerships, UNEP helps people working in sectors such as agriculture, fisheries, forestry and tourism to incorporate environmental concerns into their work (UNEP, 2020).

\subsubsection{Ten Principles of the UN Global Compact}

The strategy of the UN Global Compact was launched in 2000 by Kofi Annan, former UN Secretary General and it is to drive business awareness and action in support of achieving the Sustainable Development Goals (SDGs) by 2030. By respecting and supporting universal principles, UN Global Compact business participants can play an important role in helping to realize the SDGs. Recommendations for a carbon neutral world by the end of the century through our partnership with $\mathrm{CO}_{2}$ logic, and are developing a low carbon strategy based on the Science Based targets initiative to stay within a 2-degree trajectory towards 2100 (DPD Group, 2018).

Corporations are increasingly recognizing the link between good business and respecting human rights. This is reflected in the more than 12.000 corporate participants and other stakeholders from over 145 countries in the UN Global Compact, the largest voluntary corporate responsibility initiative in the world. It is a practical framework for the development and implementation of sustainability policies and practices to help advance sustainable business models and markets (Portalewska, 2015).

\subsubsection{ISO 140001}

ISO 14001 is an internationally agreed standard that sets out the requirements for an environmental management system. It helps organizations improve their environmental performance through more efficient use of resources and reduction of waste, gaining a competitive advantage and the trust of stakeholders. ISO 14001 is suitable for organizations of all types and sizes, be they private, not-forprofit, or governmental. It requires that an organization considers all environmental issues relevant to its operations, such as air pollution, water and sewage issues, waste management, soil contamination, climate change mitigation and adaptation, and resource use and efficiency. ISO 14001 includes the need for continual improvement of an organization's systems and approach to environmental concerns (ISO, 2015).

ISO 14001:2015 has been revised and requires now as following (ISO, 2015):

- Environmental management to be more prominent within the organization's strategic direction.

- A greater commitment from leadership.

- The implementation of proactive initiatives to protect the environment from harm and degradation, such as sustainable resource use and climate change mitigation.

- A focus on life cycle thinking to ensure consideration of environmental as- 
pects from development to end-of-life.

- The addition of a stakeholder-focused communication strategy.

\subsubsection{ISO 26000}

ISO 26000 is intended to assist organizations in contributing to sustainable development. It encourages them to go beyond legal compliance, recognizing that compliance with the law is a fundamental duty of any organization and an essential part of their social responsibility program. When applying ISO 26000, organizations should consider societal, environmental, legal, cultural, political, and organizational diversity as well as differences in economic conditions, while being consistent with international norms of behavior. ISO 26000 is not a management system standard. It does not contain requirements and, as such, cannot be used for certification. Any offer to certify, or claims to be certified, against ISO 26000 would be a misrepresentation of its intent and purpose (ISO, 2018).

\subsubsection{EMAS}

The EU Eco-Management and Audit Scheme (EMAS) is a premium management instrument developed by the European Commission for companies and other organizations to evaluate, report, and improve their environmental performance. EMAS is open to every type of organization eager to improve its environmental performance. It spans all economic and service sectors and is applicable worldwide. EMAS is the ideal complement to ISO 14001 and allows organizations that are already certified by ISO 14001 (European Commission, 2020).

EMAS stands for:

Performance: EMAS supports organizations in finding the right tools to improve their environmental performance. Participating organizations voluntarily commit to both evaluating and reducing their environmental impact.

Credibility: Third party verification guarantees the external and independent nature of the EMAS registration process.

Transparency: Providing publicly available information on an organization's environmental performance is an important aspect of EMAS. Organizations achieve greater transparency both externally through the environmental statement and internally through employees' active involvement.

\subsection{Environmentally Friendly Delivery Vehicles}

\subsubsection{Electrically Assisted Cargo Bikes (Cargo eBike)}

A cargo eBike is equipped with battery-powered electric motors that make it possible to cover longer distances, carry substantial loads and navigate hills and other terrain. Maximum energy efficiency is achieved when combining battery power and human power simultaneously. The e-Bikes work in combination with a centralized container, which can be brought into the city during non-peak hours (UPS \& GreenBiz, 2017).

Moreover, the commercial cargo bike is usually simple to use. Parcel drivers do not need any other driving license. Parcel delivery drivers could control an 
electrically assisted bike comfortable in a short time, even they do not have any prior experience before. Many technology equipment, such as GPS and small board computer, could be installed in the cargo bikes, to improve the information exchange. Cargo bike combines a bicycle and a small electric minivan could become one of the most effective last mile logistic vehicle on the sorrow streets of urban areas.

\subsubsection{Electric Parcel Delivery Vehicles}

Over the next 10 to 20 years, sustainable fuels will play a critical role in efforts to reduce the impact of transport on the climate. The growing shift towards sustainability is driven largely by consumer demand and by regulations requiring companies to reduce carbon emissions and production waste. Electromobility meets all of the criteria to become the ideal solution in decarbonizing transport. Battery powered e-vehicles produce zero emissions and are quiet. Small zero-emission vans for deliveries in cities are the ideal solution for couriers (DHL Group, 2019).

At present, many shippers and drivers have unsatisfied experience with the electric vehicle's implementation in city logistics. The most important problem is the lesser performance of electric vehicles in comparison to the conventional engines. However, in recent years the significant technical improvements have been made in this area as well as many efficient electric vehicles have been offered on the market (Iwan et al., 2014; Wątróbski et al., 2017).

Many EU governments have set the ambitious targets. For example, Germany has launched a campaign to put 1 million e-vehicles on the road by 2020. In 2009, according to the Federal Ministry for Economic Affairs and Energy of Germany, different related ministries promoted a plan to develop Germany as a leading electric mobility market. In connection to this the goal of one million electric vehicles. Denmark has tax exemption scheme that promotes the usage of light duty electrical vehicles. This tax scheme has changed over time. Initially, electrical vehicles were completely free from paying registration tax. Later this changed and the electrical vehicles were exempted $80 \%$ of the registration tax, starting in 2016, and then the precentral exemption decreases by $20 \%$ per year until 2020 (Iwan \& Allesch, 2019). According to the result of survey, majority of participants agree that electric vehicle should be used for urban logistic and it should have over $50 \%$ share of parcel delivery vehicle in next five to ten years.

\subsection{Personal Management of Parcel Delivery Company}

According to the survey of e-commerce users in Germany, the service quality of parcel delivery drivers is the most critical point. Firstly, parcel drivers might not try to deliver parcels to customers at all, even customers have been waiting for the receiving at home all day. This problem could happen more often if the customers live at the high floors. Secondly, parcel delivery drivers leave often wrong parcel information for customers while nobody at home. As a result, customers must find their parcels by themselves from the neighbors, parcel shops, parcel 
stations or even by strangers.

Many parcel delivery business companies have underestimated the importance of employee engagement. Without employee engagement, parcel delivery business companies may face to lose their competition abilities for long term. Usually, parcel delivery drivers are the only people, who need to contact with customers personally while the whole parcel delivery process. Therefore, parcel delivery business companies should improve their employer brand to obtain the attractiveness for the employees as well as the potential employees.

Providing a mindful, respectful, and ethical workplace for all employees and partners forms the foundation of the business and an aim to which all contribute to the day-to-day practices (DPD Group, 2018). In addition, providing the additional training for parcel drivers is necessary to the parcel delivery companies. The training contains should teach their parcel drivers, for example how to use technical equipment exactly, how is the more efficient delivery process and how to deal with customers in practice. After the training, parcel drivers will have higher productivity and engagement during the work.

\subsection{New Stationary Parcel Shops}

\subsubsection{Advantages of the Parcel Shops for Urban Last Mile Logistic}

Stationary parcel shops could become an ideal solution to the parcel reception in B2C sector. Delivery to stationary parcel shops is a flexible way for customers to receive parcel compare with home delivery. Customers do not need wait for the parcels at home for whole day and they do not need fear of loss parcel information after the failure of home delivery. Customers could choose parcel directly deliver to a parcel shop, which located in the near home, or the parcels will be delivered into the next parcel shop from home of the customers, if the first home delivery failed. On the other hand, for parcel delivery companies, the costs of last mile delivery will reduce significantly because parcels will successfully be delivered within a shorter process. That means the fuel costs and staff costs could be spend for the parcel delivery companies. At the same time, they can get higher customers' satisfaction. Furthermore, with reducing of drive routes the output of $\mathrm{CO} 2$ emission and noise from delivery vans or trucks will go down, it is a meaningful contribution to improving of city environment.

\subsubsection{Logistics Process of New Parcel Shop}

Firstly, parcel delivery driver can find information about the total storage capacity via a mobile application software (App), free storage capacity, free volume for oversize and overweight parcels and distance to the next parcel shop. Before parcels delivered to the shops, parcel drivers should reserve for the storage capacity, to ensure the enough places for their parcels.

After the reservation, parcels can be delivered into parcel shops. All parcels will be scanned while it is loading on the conveyor belt. After scanning, tracking information will be update and put into the Enterprise-Resource-Planning (ERP) 
system of the parcel shop. At same time, this tracking information and a digital barcode will be sent to customers automatically for pickup via their chosen way. Then the parcels will be continuous to transport into the reserved storage place through the conveyor belt, and the parcel loading process is completed (see Figure 2).

(1)

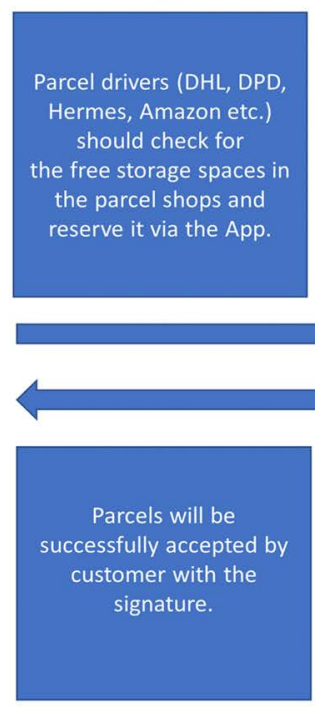

10
(2)

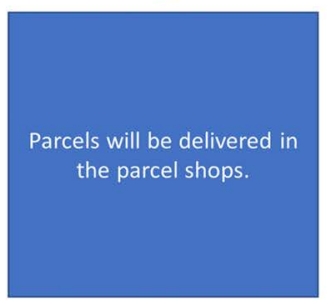

3

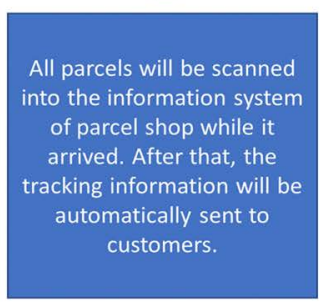

(4)

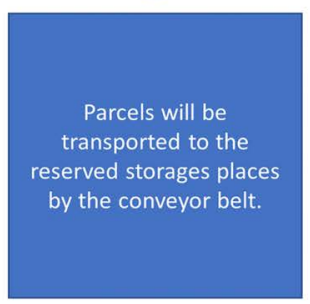

5

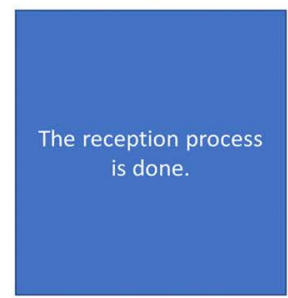

Tracking information will

be identified through

scan of the QR Code by

the information system of

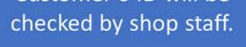

(9)
The parcels will be found out

automatically by the robotic

arms from parcel storages.

\section{parcel shop.}

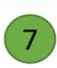

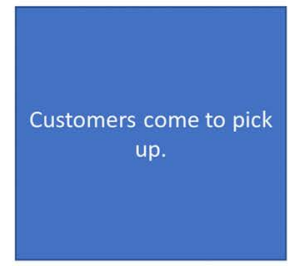

6

Figure 2. Logistic processes of parcel shops; Source: author's own creation.

Now customers would come to parcel shop to pick up their parcels. At first, shop staffs can quickly find out the parcels from storage through the identification of barcode. Then, parcels will be transported to the position of check out by the conveyor belt. The identity card of customers will be checked by staffs. If everything has been done, customers can sign at the surface of the system and the pick-up process is finish.

\subsubsection{Location and Shop Design}

The new parcel shops will be only located in the urban residential areas with high population density. The service scope of a parcel shop should be approximately one square kilometer. Within this area the customers can come to the parcel shop by foot. Another advantage of this location strategy is that, in the residential areas the rental fee is normally lower than in the business areas. Furthermore, the competition is not much intense. These advantages can help the new parcel shops reduce its fix costs and increase the business benefits.

The total shop space should be between 60 square meters and 100 square meters. Over 100 square meters leads to high rental fees and limited selection. On the other hand, if shop is too small, the storage space could be reduced, and the turnover will decrease. A suitable shop space could have a balance among the costs and turnover. 
The shop space will be divided to a sales area, a parcel storage area, and a small office area (layout is indicated in Figure 3). Every area should be clearly separated from each other due to a better management responsibility. For the personal safety, customers should be only allowed to enter the sales area and alcohol drinking is not possible in the shops. Some seats and tables will be established on the window, which could provide a short break time for customers. Design of the parcel shop should be neutrally, informatively and energy economically.

The fast-moving consumer goods (FMCG) and other daily life required products are available in the shops. Customers can purchase variety products in the shops during the parcel pick-up. Moreover, people can quickly get the products at the parcel shops without a long waiting time for check out. That is important for the people, who need go to work in the morning. In the summer, the ice cream will be sold in the shops as well.

The parcel storage area should be established behind of the sale area. Storage shelves of the different parcel service companies will be separated clearly to ensure the efficiency of loading and outlet processes. In the future, the robotic technology will be utilized for these processes. The total storage capacity is fixed calculated. For oversize and overweight parcels, a special space should be built in the parcel storage area with an extra capacity. Before next oversize and overweight parcel arrived, the free volume should be checked by parcel drivers via the App.

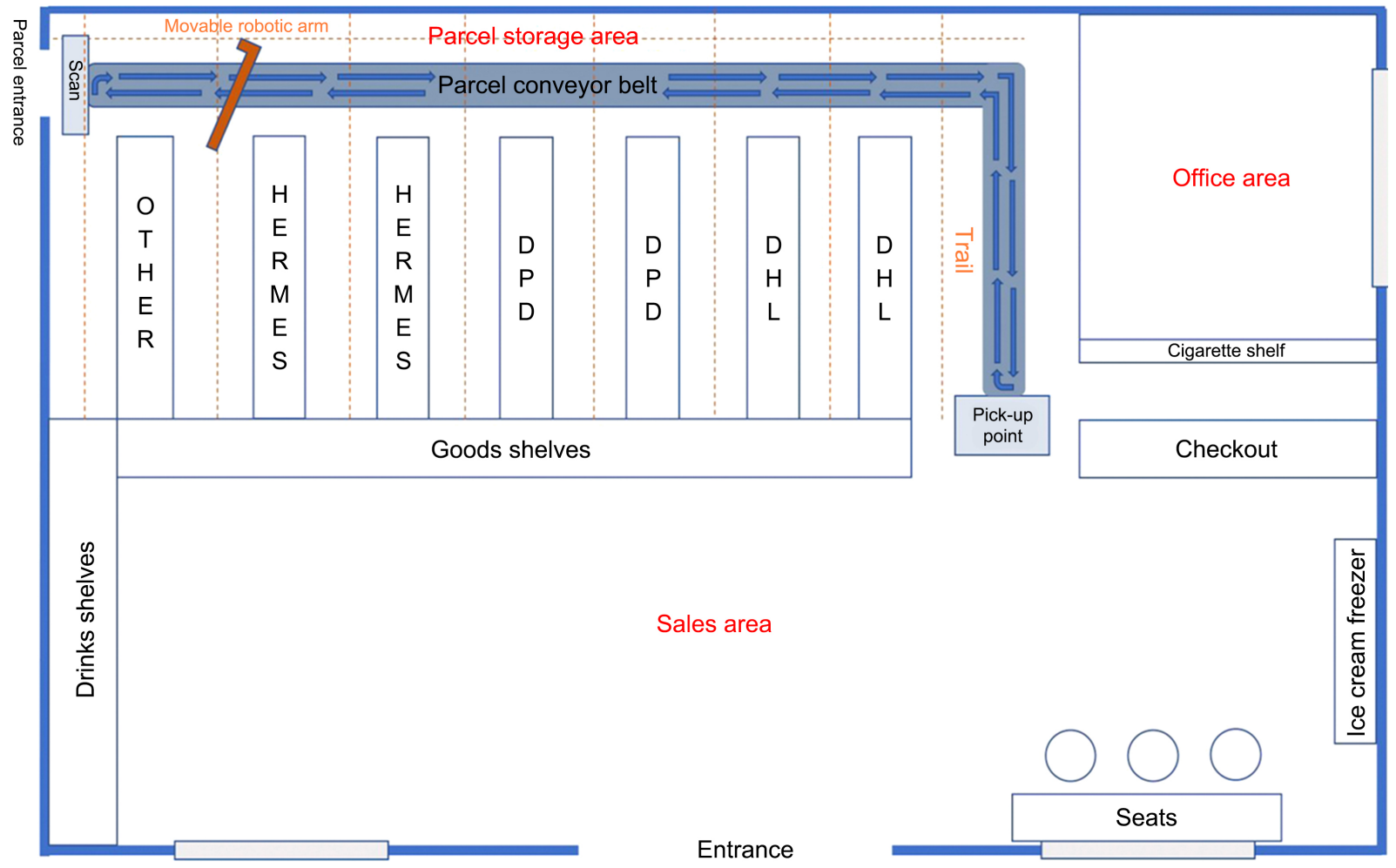

Figure 3. Plan for the new multi-functional parcel shops; Source: author's own creation. 
In addition, a small office area is necessary for the parcel shop. Staffs can process daily administrative tasks and take a break in this area. Most of technology equipment for the shops will be set up here as well.

\subsubsection{Integrational Information Systems}

As a part of the ERP system of the new parcel shop, an integrational parcel management system program should be developed. The aims of this program are to build a connected tracking information for customers and have a high parcel storage efficiency in the shop.

The tracking information of the different logistic companies should be connected into the parcel management program. This information will be transformed into a special barcode of the parcel shop. Customers will receive this barcode once the parcels are delivered in the shop and can pick up their parcels with this barcode directly. The changing of the current tracking systems of logistic companies is not necessary, because all information is based on the barcode.

A smartphone App of the new parcel shop is another way for customers. Through this App customers can check the tracking information of their parcels and extend the storage time if they cannot pick up the parcels in time. This App has also a business interface for the logistic companies. Parcel drivers can access the App in their smart parcel scanner to check the storage capacity and reserve place in the parcel shop.

The parcel management program is also connected with the robotic arms. According to this program, the robotic arms can support to operate the parcel storage process. In facing on the fast increasing of the number of parcels, this parcel management system will become one of the most important management methods for the parcel shop logistic process.

\subsubsection{Parcel Storage Management}

Parcel storage is established behind of the sales area in the parcel shop. In term of personal safety and management needs, usually customers are not allowed to enter this area.

The expired parcels will be warned by the parcel management system automatically and returned to the retailers on time. Customers can extend the storage time once for five days via App before their parcels expired. The extend information will be noticed in the parcel system.

Due to the limited storage space, the oversize and overweight parcels can only be accepted at the parcel shops, if the drivers have made the reservation. If there is no free space, oversize and overweight parcels will be delivered to the next parcel shop.

In the beginning phase of the new parcel shops, staffs will handle the parcel storage personally. In the next five to ten years the whole storage management process should be operated automatically. That means, the robotic technology will be developed and integrated into the parcel management system, so that the whole parcel storage management process is highly efficient. 


\subsubsection{Automatic Robotic Technology}

The main function of the robot technology is designed to manage the loading and outlet processes of parcels. The control of the robotic arm will be integrated into the parcel shop management system. A robotic arm will be established on the roof (or on the wall) in the storage area for parcel distribution and pick up from the shelves. The robotic arm can move along the trails among the parcel shelves (the structure presents in Figure 3). Every logistic company has own parcel shelves. While the parcels are arriving in the parcel shop, they will be scanned at the point of entrance. Then the robot arm will put them to the reserved space on the shelves.

A parcel conveyor belt will be installed on the ground in the parcel shop for transfer the parcels from shelves to customers. During the parcel return process, customers give the parcels to staffs at the checkout point. Then parcels will be put it on the conveyor belt by staffs and scanned automatically. Robotic arm will carry the parcels to the return space for the correspond companies. As parcel drivers come to pick up the return, the robotic arm will put all parcels on the conveyor belt. The robot arm will be informed by staffs which company is coming.

The robotic arm can carry all standard sizes parcels, but not suitable for the oversize and overweight parcels. For the oversize and overweight parcels, the electric hand forklifts should be available for the staffs. As value added service, the parcel shop provides the delivery service of oversize and overweight parcels for the customers.

With the automatic technology, the parcels can be found and carried to customers quickly. Also, for the staffs, they won't have safety problem during the handling with oversize and overweight parcels.

\section{Conclusion}

Meet to the trend of urbanization and fast developing of e-commerce, how to handle with urban last-mile delivery sustainably is becoming the key to managing of an effective urban logistics. A sustainable urban last-mile delivery concept should consider to the needs of e-commerce customers, the economic successes of logistics companies, and the public interesting in sustainability.

On the one hand, the sustainable regulations and standards should be released by governments and be controlled stringently. On the other hand, logistics companies should improve their sustainable management abilities and obtain the corporate society reasonability (CSR) to fill the expectations of customers to the sustainability. In term of the complexity of urban logistic conditions, sustainable urban last-mile delivery could only be successfully implemented under the cooperation with extensional stakeholders, such as public administration, entrepreneurs, academics, Non-governmental organizations (NGOs), and citizens.

\section{Limitations and Future Research Directions}

This paper is limited to the research of one parcel shop in Germany. In terms of 
diverse local situations and requirements, future research should extend the range of parcel shops and increase the sample of e-commerce users. Due to collection of the most representative data, target groups and locations of parcel shops should be cautiously selected with detailed criteria before beginning of next research.

Moreover, future researchers might connect sustainable urban last mile delivery into a digital and automatic technology-based smart city concept, for example, how to integrate information system of parcel vans with parcel shops and how to use artificial intelligence (AI) technology to choose the most effective delivery route. Amount of investment and elevation of corresponding technology providers might be the other focuses for future research.

\section{Conflicts of Interest}

The authors declare no conflicts of interest regarding the publication of this paper.

\section{References}

Aranko, J. (2013). Developing the Last Mile of a Parcel Delivery. Espoo: Laurea University of Applied Sciences.

Awwad, M., Shekhar, A., \& Iyer, A. (2018). Sustainable Last-Mile Logistics Operation in the Era of Ecommerce. Proceedings of the International Conference on Industrial Engineering and Operations Management, Washington DC, 27-29 September 2018, 584-591.

Browne, M., Macharis, C., Sanchez-Diaz, I., Brolinson, M., \& Billsjö, R. (2017). Urban Traffic Congestion and Freight Transport: A Comparative Assessment of Three European Cities. Proceedings of the Interdisciplinary Conference on Production, Logistics and Traffic, Darmstadt, 25-26 September 2017, 1.

Capgenini (2019). The Last-Mile Delivery Challenge. Paris: Capgemini Research Institute.

DHL Group (2019). Sustainable Fuels for Logistics. Bonn: Deutsche Post AG.

DHL Group (2020). Green Energy Logistics.

https://www.dhl.com/global-en/home/insights-and-innovation/thought-leadership/tre nd-reports/green-energy-logistics.html

DPD Group (2018). Corporate Social Responsibility Report 2018. Issy Les Moulineaux: DPD Group.

European Commission (2020). What Is EMAS.

https://ec.europa.eu/environment/emas/index_en.htm

Faccio, M., \& Gamberi, M. (2015). New City Logistics Paradigm: From the "Last Mile" to the "Last 50 Miles" Sustainable Distribution. Sustainability, 7, 14873-14894.

https://doi.org/10.3390/su71114873

Fehrenbacher, K. (2020). Trend: Last-Mile Transportation Inches Closer to Home. https://www.greenbiz.com/article/trend-last-mile-transportation-inches-closer-home

FORBA (2018). Precarious Working Conditions in the Parcel Services: To Take a Stand and Deliver Our Message. Wien: Vida.

ISO (2015). Introduction to ISO 14001:2015. Geneva: International Organization for Standardization. 
ISO (2018). Discovering ISO26000. Geneva: International Organization for Standardization.

Iwan, S., \& Allesch, J. (2019). Electric Mobility in European Urban Freight and Logistics-Status and Attempts of Improvement. Transportation Research Procedia, 39, 112-123. https://doi.org/10.1016/j.trpro.2019.06.013

Iwan, S., Kijewska, K., \& Kijewska, D. (2014). Possibilities of Applying Electrically Powered Vehicles in Urban Freight Transport. Procedia-Social and Behavioral Sciences, 151, 87-101. https://doi.org/10.1016/j.sbspro.2014.10.010

Lan, S., Tseng, M.-L., Yang, C., \& Huisingh, D. (2020). Trends in Sustainable in Major Cities in China. Science of the Total Environment, 712, Article ID: 136381. https://doi.org/10.1016/j.scitotenv.2019.136381

Mesjasz-Lech, A. (2016). Urban Air Pollution Challenge for Green Logistics. Transportation Research Procedia, 16, 355-365. https://doi.org/10.1016/j.trpro.2016.11.034

OECD (2020). Smart Cities and Inclusive Growth. Paris: Organisation for Economic Co-Operation and Development.

Park, M., \& Regan, A. (2004). Issues in Emerging Home Delivery Operations. Irvine, CA: University of California.

Portalewska, A. (2015). Changing the Way Business Is Done. https://www.culturalsurvival.org/publications/cultural-survival-quarterly/changing-wa y-business-done-un-global-compact

Schaer, C. (2018). The Dark Side of Germany's Online Shopping Boom. https://www.handelsblatt.com/english/companies/courier-rights-the-dark-side-of-ger manys-online-shopping-boom/23694948.html

Schöder, D., Ding, F., \& Campos, J. (2016). The Impact of E-Commerce Development on Urban Logistics Sustainability. Open Journal of Social Sciences, 4, 1-6.

https://doi.org/10.4236/jss.2016.43001

Siegfried, P. (2013). The Importance of the Service Sector for the Industry, Teaching Crossroads: 9th IPB Erasmus Week (pp. 13-23). Instituto Politécnico de Braganca.

Siegfried, P. (2014a). Knowledge Transfer in Service Research-Service Engineering in Startup Companies, EUL-Verlag.

Siegfried, P. (2014b). Onlinehandelerfolgreiche Unternehmenskonzepte (Volume 2). AVMAkademische Verlagsgemeinschaft München.

Statista (2020a). Courier, Express and Parcel (CEP) Market Size Worldwide between 2009 and 2019.

https://www.statista.com/statistics/723986/cep-market-total-revenue-worldwide

Statista (2020b). E-Commerce Worldwide. https://www.statista.com/outlook/243/100/ecommerce/worldwide

UN Environment Programme (UNEP) (2020). Why Does Environmental Rights and Governance Matter?

https://www.unenvironment.org/explore-topics/environmental-governance/why-doesenvironmental-governance-matter

UPS \& GreenBiz (2017). The Road to Sustainable Urban Logistics. Atlanta, GA: United Parcel Service of America and Oakland: GreenBiz Group.

Van Amstel, W. (2017). The Future of Last Mile Delivery: 10 Most Important Trends. https://www.kennisdclogistiek.nl/nieuws/the-future-of-last-mile-delivery-10-most-imp ortant-trends

Van Audenhove, F.-J., De Jongh, S., \& Durance, M. (2015). How to Unlock Value from Last Mile Delivery for Cities, Transporters and Retailers. Brussels: Arthur D. Little. 
Wang, Y., Zhang, D., Liu, Q., Shen, F., \& Lee, L. (2016). Towards Enhancing the LastMile Delivery: An Effective Crowd-Tasking Model with Scalable Solutions. Transportation Research Part E: Logistics and Transportation Review, 93, 279-293. https://doi.org/10.1016/j.tre.2016.06.002

Wątróbski, J., Małecki, K., Kijewska, K., Iwan, S., Karczmarczyk, A., \& Thompson, R. (2017). Multi-Criteria Analysis of Electric Vans for City Logistics. Sustainability, 8, 1453. https://doi.org/10.3390/su9081453

Weekes, S. (2020). E-Commerce Delivery Emissions on Track to Increase 30\% in Cities by 2030 .

https://www.smartcitiesworld.net/news/news/e-commerce-deliveries-could-see-30-rise -in-city-carbon-emissions-4931

Young, J. (2019). Global Ecommerce Sales to Reach Nearly \$3.46 Trillion in 2019.

https://www.digitalcommerce360.com/article/global-ecommerce-sales 